\title{
Pedagogía y Psicología en la mejora de las prácticas docentes
}

\section{Pedagogy and Psychology for Improvement of Teachers' Practices}

\author{
Jorge Rodríguez-Sosa
}

Universidad San Ignacio de Loyola, Lima, Perú.

Un tema recurrente en el mundo académico y en la agenda política latinoamericana de hoy es el de las múltiples brechas que caracterizan a nuestra educación: brechas de desempeño entre la escuela pública y privada, entre la escuela urbana y rural, de género, en los niveles socioeconómicos de las familias, entre otras. Una de estas brechas tiene que ver con el hecho de que las escuelas enfrentan la necesidad de alinear o, al menos, acercar lo que están en capacidad de ofrecer, incluido aquello que sus docentes entregan cotidianamente, y las necesidades reales de los estudiantes.

La llegada de nuevos usuarios desde realidades distintas a las que normalmente la escuela respondía, que traen nuevas subjetividades y necesidades emergentes, ha llevado a que las brechas entre el estudiante ideal (aquel estereotipo que los docentes esperan encontrar en sus aulas y sobre los cuales elaboran sus propuestas formativas) y el estudiante real (el que efectivamente se instala en las aulas) sean muy grandes. Sin embargo, a pesar de que los docentes conviven con estas brechas y las perciben con claridad, no muestran las capacidades necesarias ni las disposiciones para intentar cerrarlas. Lo que se tiene es un conocimiento "enlatado" que, por el uso repetido, es asumido como "natural", que lleva al docente a la inercia y a la reproducción de las brechas mencionadas, cuando no a su ensanchamiento.

Frente a esa situación, lamentablemente los programas de formación docente en servicio mantienen enfoques tradicionales, limitados a contenidos y/o el fortalecimiento de didácticas, implementados desde lógicas remediales y prescriptivas. Por lo general, sus propuestas no toman en cuenta el contexto de las escuelas ni la necesidad de formar en la práctica y desde la cotidianeidad del aula. Son programas estandarizados que han tenido poco impacto en el fortalecimiento de las capacidades de los docentes y en el mejoramiento de sus prácticas. Por ello, es 
poco común en nuestro magisterio observar intentos de alinear aquello que se hace con las características y necesidades de los grupos a los que se atiende, cuando ese esfuerzo de ajuste debiera ser la norma.

Es necesario introducir cambios radicales en las políticas y prácticas de desarrollo profesional docente si se quiere tener los resultados deseados. Al respecto, la investigación en el campo ofrece un conjunto de lecciones, elegibles entre las experiencias más exitosas, que recomiendan proveer espacios para el trabajo colaborativo, promover la reflexión crítica y el cuestionamiento de lo que se hace, incluyendo los conocimientos que se tienen, las metodologías que se emplean, las creencias que les dan sustento, las motivaciones y las expectativas. Al parecer, la reflexión, la negociación y el acuerdo, que son condiciones necesarias para el cambio, se dan en espacios cuya disposición organizacional y psicológica es favorable, en los que prevalece la escucha activa, la crítica y la flexibilidad. Es en este punto que el trabajo conjunto y complementario entre Pedagogía y Psicología resulta indispensable.

Propósitos y Representaciones no es ajena a la preocupación mostrada. Por el contrario -y tal como se aprecia en los artículos que encontrarán a continuación-, estos temas son abordados de manera directa o tangencial. En este número, los artículos de Ayllón, Gómez y Ballesta-Claver, de Roselli y de Cortez, La Torre y Hernández, presentan nuevas formas de trabajo docente en el aula, en el sentido exigido por las necesidades de cambio educativo sobre las que hemos reflexionado párrafos arriba. El artículo de L. Rodriguez, Gallego y A. Rodríguez es novedoso: reflexiona sobre la arquitectura adecuada para una formación profesional flexible. Finalmente, los trabajos de Caycho, de Barahona y Alegre, y de Arboccó, observan variables psicológicas diversas en el marco de distintos acercamientos.

\section{Correspondencia}

Email: jrodriguezs@usil.edu.pe

\section{Citar como:}

Rodríguez-Sosa, J. (2016). Pedagogía y Psicología en la mejora de las prácticas docentes. Propósitos y Representaciones, 4(1), 07-10 doi: http://dx.doi.org/10.20511/pyr2016. v4n1.95

(C) Universidad San Ignacio de Loyola, Vicerrectorado de Investigación y Desarrollo, 2016.

(๕) BY-NC-ND Este artículo se distribuye bajo licencia CC BY-NC-ND 4.0 Internacional (http://creativecommons.org/licenses/by-nc-nd/4.0/). 